\title{
MITIGATION OF VOLCANIC RISK: THE COSMO-SKYMED CONTRIBUTION
}

\author{
Patrizia Sacco $^{(1)}$, Maria Girolamo Daraio ${ }^{(1)}$, Maria Libera Battagliere ${ }^{(1)}$ and Alessandro Coletta $^{(1)}$, \\ ${ }^{(1)}$ Italian Space Agency (ASI), Via del Politecnico s.n.c., 00133, Rome, Italy, Email: patrizia.sacco@est.asi.it
}

\begin{abstract}
The Italian Space Agency (ASI) promotes Earth Observation (EO) applications related to themes such as the prediction, monitoring, management and mitigation of natural and anthropogenic hazards. The approach generally followed is the development and demonstration of prototype services, using currently available data from space missions, in particular the COSMO-SkyMed (Constellation of Small Satellites for Mediterranean basin observation) mission, which represents the largest Italian investment in Space System for EO and thanks to which Italy plays a key role worldwide. Projects funded by ASI provide the convergence of various national industry expertise, research and institutional reference users. In this context a significant example is represented by the ASI Pilot Projects, recently concluded, dealing with various thematic, such as volcanoes. In this paper a special focus will be addressed to the volcanic risk management and the contribution provided in this field by COSMOSkyMed satellite constellation during the last years. A comprehensive overview of the various national and international projects using COSMO-SkyMed data for the volcanic risk mitigation will be given, highlighting the Italian contribution provided worldwide in this operational framework.
\end{abstract}

\section{INTRODUCTION}

Volcanic eruptions are spectacular events that differ from other natural hazards because they are located in fixed-areas of the Earth. Studying these natural phenomena is therefore a matter of primary importance. Remote sensing has increased throughout the last decades and has became a popular tool for observing the numerous active volcanoes throughout the world. Actually, volcanic processes can occur far below the Earth's surface, therefore not being visible to the naked eye. Among the various remote sensing techniques, radar satellites provide a powerful tool to help study and understand the structure of a volcano. Radar interferometry is used for two main reasons: 1) to examine the topography of a volcano and 2) to map surface changes such as lava flows or deformations. This helps in providing a safe environment as well as decreasing the amount of on-site information needed. By bouncing signals from a radar satellite off the ground in successive orbits and looking at the differences between the images, Interferometric Synthetic
Aperture Radar (InSAR) can detect small differences in the distance between its position and the ground. InSAR shows spatial patterns of deformation in remarkable detail and, in combination with ground-based monitoring, gives scientists unprecedented insight into a wide range of earth science processes. Researchers said the findings suggest deformation can be a good indicator of eruptions, as satellite radar can be used to identify volcanoes "bulging with magma" which can then be investigated from the ground.

In this context, thanks to its unique characteristics such as the high temporal resolution, COSMO-SkyMed can improve the knowledge of volcanoes dynamic processes and thus give support in the definition of any emergency plan.

\section{COSMO-SkyMed MISSION OVERVIEW}

The 2003-2005 ASI National Space Plan has foreseen the realization of an Earth Observation Dual Use System, the COSMO-SkyMed System, for the monitoring of Resources, Natural Disasters and National Security having as its main goal the improvement of the planet Earth knowledge, of its natural and its anthropic phenomena as well as the quality of life and the citizen level of safety. The observation of the territory, through the elaboration of satellite images is, in fact, an essential tool for providing homogeneous information.

Italy plays a crucial role at world level thanks to the planning, realization, launch and operational activities the COSMO-SkyMed satellites constellation which is Italian biggest investment in the Earth Observation field.

The management of the system is coordinated by the Italian Space Agency with the support of the Italian Ministry of Defence. COSMO-SkyMed is a dual (civil and military) multi mission system, able to integrate itself with other space systems so as to satisfy the needs of a wide community of users. Thanks to its unique characteristics, it can observe any part of our planet, under any weather and lighting (day/night) condition providing high resolution space images in very short times.

The COSMO-SkyMed system is based on the following elements:

- a Space Segment made of a constellation of 4 satellites equipped with SAR (Synthetic Aperture Radar) sensors operating in $\mathrm{X}$ band and equipped 
with a highly innovative and flexible system for acquiring and transmitting data;

- a Ground Segment made of geographically distributed infrastructures for:

the management and the control of the whole constellation;

- the reception of observation requests and the relevant activities of planning and programming;

the reception, filing and elaboration of relevant data as well as the distribution of generated products;

thanks to its ability of expansion through the addition of more programming and production data which may be deployed in any worldwide site, it may operate together with other systems;

an integrated logistics and operations segment which allows the operational management of the constellation according to efficiency and cheapness criteria, thus guaranteeing the same management even in the case of expansion of the system through the addition of further programming stations and production of data.

The launch of the fourth satellite of the constellation, occurred in November 2010, completed the first generation constellation, which is fully operative since May 2011, and thus guaranteeing a global revisit time in the order of 12 hours (worst case) for the $100 \%$ of the Earth sites (in the nominal configuration).

Thanks to its flexibility, COSMO-SkyMed system "modulates" the response time depending on the actual needs, by setting the current system operative mode to either routine, or crisis, or very urgent mode, each corresponding to a mission chronology appropriate to the mission activities currently in execution.

In routine mode the system is able to satisfy a user request (Response Time) within 72 hours; in crisis mode within 36 hours and in very urgent mode (acquisition plan uploaded asynchronously) within 18 hours.

By using the available system resources, and setting the appropriate operative mode, the COSMO-SkyMed system response time can be significantly shorten to few hours in the zone of interest, which makes it particularly suitable in responding to emergency cases, such as volcanoes eruptions, and in providing valuable information to support operations in a tactical scenario. A more detailed description of the COSMO-SkyMed architecture is available in [1].

The other factor which strongly characterizes COSMOSkyMed architecture and performances is the versatility of its SAR instrument, in terms of imaging resolution and swath size. Indeed, the COSMO-SkyMed SAR imaging capabilities span from the very high resolution of "Narrow Field" images taken in Spotlight mode up to the lower resolution of "Wide Swath" images taken in
ScanSAR mode over a huge access region.

The full COSMO-SkyMed constellation configuration can provide an acquisition capacity of up to 560 GB/day, roughly corresponding to 1800 standard images per day (typically 300 Spotlight-2 and 1500 Stripmap), which is larger than any other space observation system, thus capable to fulfill the needs of large user's communities, worldwide.

The on-line archive capacity is able to store up to 560 products; due to a new developments activity, currently this volume is increasing reaching the full constellation capability (nominally 1350 products per day). The processing chains are currently implemented to provide 200 civil products per day. The archiving and processing architecture has been designed to enlarge the capacity when the user requests increase.

\section{COSMO-SkyMed FOR VOLCANOES}

A wide variety of natural phenomena can be detrimental for the natural environment and for the anthropic structures and the human being, volcanism being among these. With COSMO-SkyMed Italy offers today an efficient response to actual needs of environment management [2],[3],[4],[5].

COSMO-SkyMed constitutes a fundamental, powerful asset for space radar observation aimed at environmental monitoring, territory surveillance, and homeland security enforcement. It is a typical example of a satellite system designed, developed and operated to support Emergency Management operations worldwide, for example in case of volcanoes monitoring [2], [3]. COSMO-SkyMed satellites can actually help to precisely investigate volcanic risk assessment framework which can be used to reduce the negative consequences of volcanic activity on people and assets. Several projects have been activated with ASI aiming at the exploitation of COSMO-SkyMed data for the volcanic risk management, the most of which are currently on-going. An overview of such projects is provided in the following sections.

\subsection{SRV}

During the last years COSMO-SkyMed has provided its contribution to the volcanic risk management starting from the ASI SRV (Sistema Rischio Vulcanico) pilot project, coordinated by INGV (Istituto Nazionale di Geofisica e Vulcanologia), which is responsible at national level for the volcanic monitoring. The SRV project started at the beginning of 2007 with the main objective to develop a pre-operative system based on Earth Observation data and ground measurements integration to support the volcanic risk monitoring of the Italian Civil Protection Department (DPC). This project demonstrated that, in order to study the volcanic processes and to produce applications for the volcanic risk management, it is necessary to have temporal series 
of data acquired in interferometry configuration and always updated over the volcanic areas.

On the basis of this considerations, a wide COSMOSkyMed images archive has been populated allowing the national and international scientific community, as well as companies developing commercial services and applications, to utilize these data for volcanic applications.

The prototypal system developed, available as WebGis interface, was tested on three test-sites: Etna, Vesuvius and Campi Flegrei [6].

\subsection{COSMO-SkyMed Background Mission}

The experience gained by previous radar missions, such as the lessons learnt coming from the operational activity with COSMO-SkyMed mission, widely demonstrated the importance to collect data over specific areas or sites of interest, in order to build a useful and sizeable archive, considering the overall user community interest and anticipating their future requirements. Such archive can be helpful for both developing new applications and providing products in a very short time to satisfy user requests, with the aim to reduce technical times needed for new data acquisitions. Initially, the COSMO-SkyMed exploitation was mostly "on demand", on the basis of specific user requests and signed agreements. When the constellation was fullydeployed and became fully-operational it was decided to exploit the wide imaging and processing capacity offered by the system implementing a well-defined Background Mission [7]. This low priority acquisition plan allowed to maximize the system exploitation during the operational lifetime of the constellation and to build up consistent data sets for the users community, generating a strategic historical data archive.

At the first step, it was evaluated that the global coverage could not be the best strategy of coverage, also considering the high degree of complexity of a dual use system, which could limit the system flexibility. For this reason, the areas of interest for the COSMO-SkyMed Background Mission were selected collecting the expression of interest related to specific sites and topics coming from the scientific and institutional community and taking into account possible customers' future needs [7].

The main area selection criteria are:

- population density (populated areas worldwide, large cities, cities, capital cities);

- economic and strategic relevance (oil and gas sites, UNESCO sites, dams, main railroads, etc);

- sensible areas (active volcanoes worldwide, seismic areas worldwide, areas subject to subsidence phenomena, glaciers). The distribution of the selected targets for this handbook is available in the following Fig. 1. Some of the main targets of the COSMOSkyMed Background Mission (update 2014) are available in the following Table 1: 163 volcanoes are regularly acquired in this context with a frequency of observation of 16 days. Their distribution is showed in Fig. 2. Almost 30.000 scenes have been acquired in the framework of the Background Mission plan addressed to volcanoes starting form 2011.

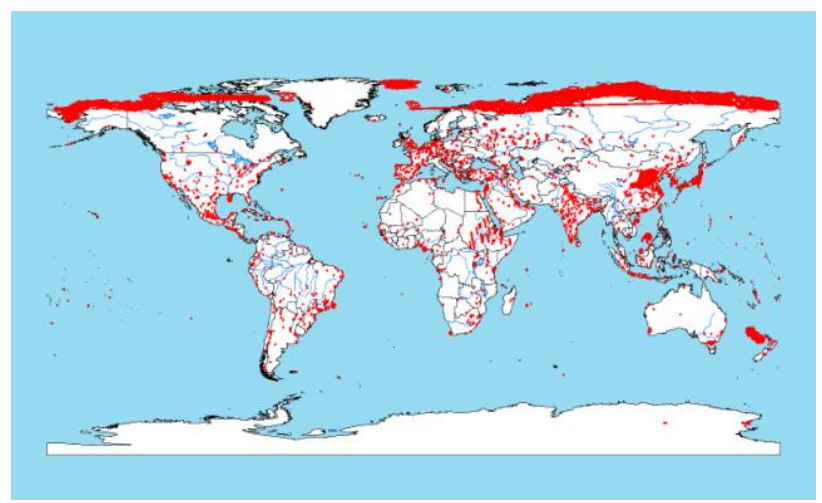

Fig. 1 - Targets distribution of one of the handbook of the COSMO-SkyMed Background Mission (courtesy of e-Geos)

\begin{tabular}{|c|c|c|}
\hline Typology & $\begin{array}{l}\text { Frequency of } \\
\text { observation }\end{array}$ & Number of Sites \\
\hline Cities & 16 days & 762 \\
\hline $\begin{array}{l}\text { Extended cities } \\
\text { (depending on } \\
\text { the number of } \\
\text { standard frames } \\
\text { to cover the total } \\
\text { area)) }\end{array}$ & 16 days & 150 \\
\hline UNESCO sites & 16 days & 264 \\
\hline Volcanoes & 16 days & 163 \\
\hline Infrastructures & 16 days & 40 \\
\hline $\begin{array}{l}\text { Oil \& Gas } \\
\text { mining }\end{array}$ & 16 days & 19 \\
\hline Subsidence & 16 days & 20 \\
\hline
\end{tabular}

Table 1 - Some of the main targets of the COSMOSkyMed Background Mission (update 2014). 


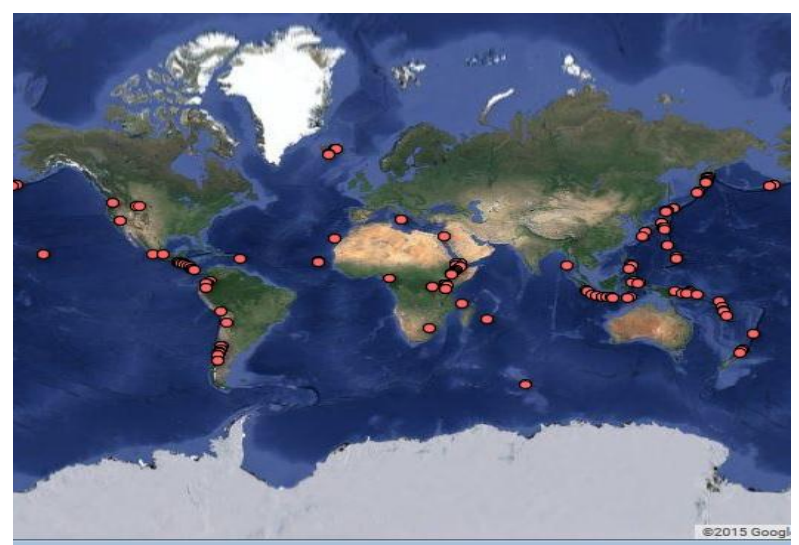

Fig. 2 - Distribution of the volcanoes monitored in the framework of the COSMO-SkyMed Background Mission starting form 2011 (Map realized using Google map 2015).

The COSMO-SkyMed Background Mission also includes other handbooks:

- Earthquake risk sites: interferometry acquisitions over areas with high seismic risk (for example, Japan, New Zealand and Iran);

- Mapping of extended areas: for example Kenya, Eritrea, Ethiopia, Djibouti, Somalia, Uganda, South Sudan and the south area of Sudan (starting from 2012).

- Global coverage of the world: this mapping started in 2014 with the coverage of the Alaska territory, selected as test-case to evaluate the operational impact of this handbook.

- Polar areas monitoring: at the end of 2014 started a new ASI acquisition plan in order to monitor some points of interest (glaciers) in Greenland and Antarctica.

\subsection{SAR4Volcanoes}

On September $18^{\text {th }} 2009$, ASI and the Japan Aerospace Exploration Agency (JAXA) signed a Memorandum of Understanding to jointly carry out disasters monitoring from space. Following this agreement, ASI and JAXA, after having agreed a Project Implementation Plan (PIP) signed on May $13^{\text {th }} 2010$ and afterwards renewed in 2011, 2012 and 2013, are now carrying out a joint activity of research for monitoring disasters from satellite based on the use of SAR data in X and L band. In this framework, they are also working together for the study of new methods and techniques which can support decisions in case of emergency. The collaboration also concerns, among the various thematic areas, the seismic and volcanic deformation. For each thematic area ASI activated national research projects, with the cooperation of other scientific organizations involved in such themes. In this context, the SAR4Volcanoes project, based on the study of volcanic deformation, has been activated [8]. This is a 2-year research project funded by ASI which focuses on volcano deformation analysis through Differential SAR Interferometry (DInSAR) techniques by means of COSMO-SkyMed and ALOS data, through the joint use X-band and L-band SAR data, supporting also the identification of methods and techniques for decision making in emergency cases. Main target volcanoes in the projects are:

- Etna, Vesuvio, Campi Flegrei and Stromboli in Italy;

- Sakurajima and Kirishima in Japan.

Secondary target volcanoes include recently or currently erupting volcanoes, as El Hierro (Spain), Nabro (Ethiopia) and Galapagos volcanoes (Ecuador). Since the beginning of the project (2011) a large amount of COSMO-SkyMed data has been acquired on the selected targets. On these premises, the project represents an important opportunity to:

(1) collect a significant amount of X-band data on active and erupting volcanoes;

(2) study surface deformation to understand magma dynamics in different volcanic settings.

\subsection{ASI participation in CEOS and GNSL initiative}

The GSNL program (Geohazard supersites and Natural Laboratories) was launched in 2012 by the "Group on Earth Observation" (GEO) with the aim of improving the scientific understanding of geological processes that could cause severe natural disasters, such as earthquakes or volcanic eruptions. Behind this project is the idea of establishing a limited number of permanent and representative sites (called "Supersites") in some areas of major interest, focusing the efforts of the international scientific community and providing all satellite and 'in situ' measurements available. Other sites, called "event supersites", may be approved in the event of particular natural disasters. The "governance" of the recently strengthened initiative is entrusted to a scientific committee and the CEOS (Committee on Earth Observation Satellites), the coordination of major space agencies dealing with Earth observation. ASI is participating to the GNSL initiative through the CEOS. The GSNL initiative has grown over the past years, particularly in late 2013 when a new supersite (precisely, Iceland) was approved, and in 2014, when other 6 new sites were approved, including two of which in Italy: Etna and the Vesuvius Campi Flegrei. Others sites are: the Marmara region in Turkey, volcanoes Cotopaxi and Tungurahua in Ecuador, volcanoes Ruapehu, Tongariro, Lake Taupo and White Island in New Zealand. An event supersite was also approved, Sinabung in Indonesia [9].

The map of the Geohazard Supersites is provided in Fig. 3. 


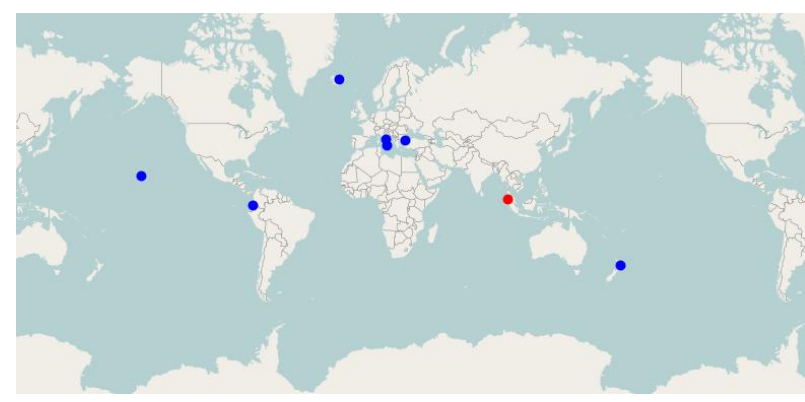

Fig. 3 - Map of the Geohazard Supersites. Blue points refer to Permanent Supersites, red point to Event Supersite [9].

\section{Hawaii Supersite}

In the first semester of 2012 ASI joined the GSNL initiative and the "COSMO-SkyMed data for GEO's Hawaii Geohazard Supersite" project started in order to gather COSMO-SkyMed data on Hawaiian volcanoes Kilauea and Manua Loa and make them available to the international scientific community within the Geohazard Supersite initiative. To expand the work of researchers that are studying Kīlauea and Mauna Loa, international Hawaii supersite scientists requested to ASI that COSMO-SkyMed data acquired prior to March 2012 be included as part of the Supersite. That time period includes the most significant fissure eruption (in March 2011) to have occurred at Kilauea since 1983. These data will permit Supersite users to build a complete time series of surface displacements stretching back several years, allowing for more thorough investigations of volcanism, earthquakes and magma-tectonic interactions in Hawaii.

\section{Iceland Supersite}

In the framework of the "COSMO-SkyMed for the Iceland Geohazard Supersite" project, the University of Iceland has signed an agreement with ASI for the provision of 500 archive images acquired before 2014 and 300 new acquisitions/year for 2014-2015 over the most active volcanoes in Iceland: Katla, Hekla, Grimsvotn and Bardarbunga.

The high frequency of COSMO-SkyMed SAR acquisitions makes it ideal for measuring fast changing ground deformations at Icelandic volcanoes. The short repeat intervals (between 1-4 days) allow scientists to detect the complex dynamics of the Icelandic volcanoes and facilitate identification of precursors to potentially disastrous eruptions.

Icelandic volcanoes have been imaged by COSMOSkyMed since 2009. Because of high latitudes, satellite acquisitions are focused in time on snow-free summer months. This is normally at maximum the time span from May to October. In Fig. 4 an overview of the acquisitions available in the COSMO-SkyMed catalogue over Iceland in the period May-October 2010 is showed.

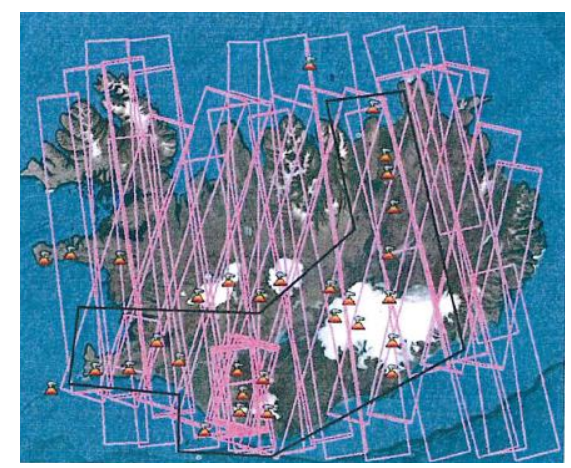

Fig. 4 - COSMO-SkyMed acquisitions in Iceland (pink rectangles) May-October 2010. The black outline marks the area where the presently most deforming and hazardous volcanoes are located.

The intense activity of the Bardarbunga volcano registered in August 2014 has brought the importance of the regular monitoring of the planet's geological risk areas to the attention of the international media. In this sense, the strategic importance of the GSNL program has been once again confirmed. An article that recently appeared in Nature [10], [11] highlighted, among other things, the contribution of the data collected by the Italian system COSMO-SkyMed. To be exact, at the request of the University of Iceland, ASI provided during 2014 more than 600 COSMO-SkyMed results on different volcanoes (Bardarbunga, Hekla, Askja, Huluhraun). These sets of data were used, along with other satellite information and in situ measurements, to follow the phases of the Bardarbunga eruption, to model the movements of magma and map the extent of the lava flow. A composite of 3 COSMO-SkyMed images acquired on 17 Jul - 2 Aug - 3 Sept 2014 processed by e-Geos, is shown in Fig. 5.

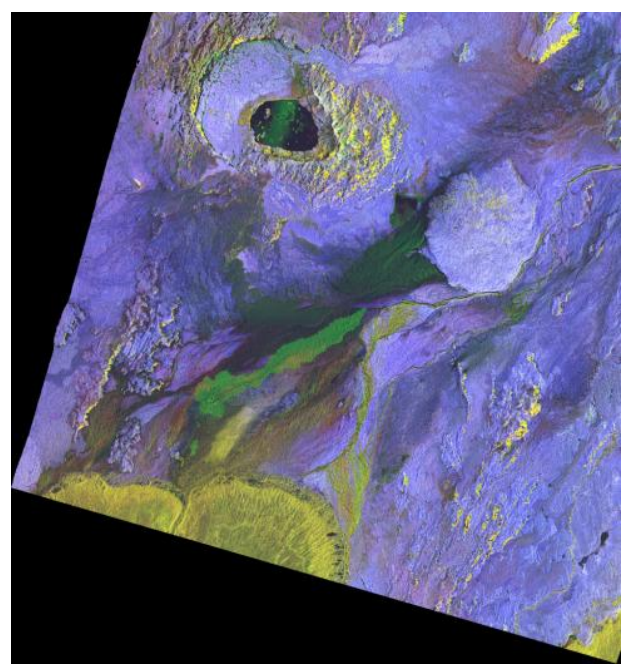

Fig. 5 - Bardarbunga volcano, Iceland. Composite of 3 images acquired on $17 \mathrm{Jul}$ - 2 Aug - 3 Sept 2014 in Stripmap Himage mode, polarization HH, Right Descending. COSMO-SkyMed (C) ASI, distributed and processed by e-GEOS. 


\section{Sinabung Supersite}

The Sinabung Supersite license agreement was signed with ASI from University of Miami in March 2014 after the approval of the Sinabung volcano, in Sumatra, Indonesia, as "Event Supersite". Sinabung has been a quiescent volcano from 1600 to 2010. In August 2010 it had its first historic eruption and a new eruptive period started in September 2013. About 25000 people living in the immediate vicinity of the volcano have been repeatedly evacuated. In the framework of this project 50 COSMO-SkyMed images, both from archive and from new acquisitions, were requested to ASI. The COSMO-SkyMed data are requested for two purposes: the first one is to resolve changes in the summit and dome area using the backscatter information. This information is of direct use for hazard assessment. The second one is to derive ground deformation data using interferometric methods in order to detect re-inflation which could indicate forthcoming eruptions.

The footprints of COSMO-SkyMed data available in the catalogue over the Sinabung volcano in the period January 2014-March 2015 are shown in Fig. 6.

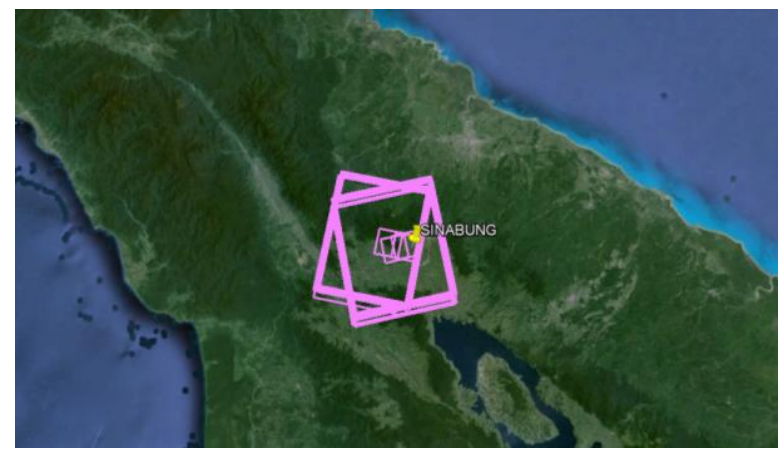

Fig. 6 - Footprints of COSMO-SkyMed images over Sinabung volcano, January 2014-March2015 (@2015 Google Earth).

\section{Marmara, Campi Flegreii-Vesuvius and Etna Supersites}

Among the 6 new supersites approved in 2014, ASI has recently activated license agreements with three of them. In particular:

- with Bagazici University for the monitoring of Marmara region through a 3-year project, for an amount of 400 COSMO-SkyMed archive images and 200 new acquisitions/year;

- with INGV - Osservatorio Vesuviano for the monitoring of Campi Flegreii-Vesuvius area through a 2-year project, for an amount of 200 COSMO-SkyMed archive images and 150 new acquisitions/year;

- with INGV - Osservatorio Etneo for the monitoring of Etna area through a 2-year project, for an amount of 350 COSMO-SkyMed archive images and 150 new acquisitions/year.

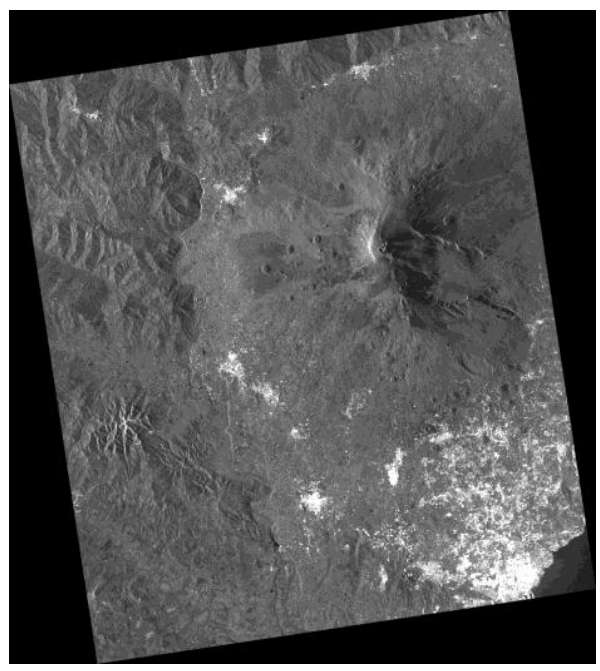

Fig.7 - Etna volcano, Italy. COSMO-SkyMed acquisition on November 24 ${ }^{\text {th }}$, 2014, Stripmap Himage mode, polarization HH, Right Ascending.

\section{CEOS DRM Volcano Pilot}

In the framework of CEOS, the Italian space Agency takes part into the Working Group Disasters activities as well, whose objective is to promote and coordinate the utilization of Space data of Earth Observation during the Disaster Risk Management (DRM) phases [12]. As part of the CEOS DRM Volcano Pilot, ASI has activated in September 2014 a 2-year project with the Cornell University for the monitoring of the volcanoes activity in Latin America, in the areas of Mexico, central America, Caribbean, Northern Andes, Galapagos, Central and Southern Andes.

An amount of 300 COSMO-SkyMed images/year, both archive and new acquisitions, are foreseen. In particular, up to March 2015, about 220 COSMO-SkyMed data have been provided over the following volcanoes: Masaya (Nicaragua), Cordon Caulle (Chile), Soufriere Hills (Montserrat), Chiles-Cerro Negro (Ecuador/Colombia), Llaima (Chile), Villarica (Chile), Hudson (Chile), Fuego (Guatemala), Turrialba (Costa Rica), Cerro Blanco (Argentina).

\subsection{Volcano Projects within AO ASI-CSA}

Among the international cooperation it is worth of mention the joint effort between Canadian and Italian Space Agencies (CSA and ASI) with an Announcement of Opportunity (AO), published at the end of 2013, aimed to stimulate the COSMO-SkyMed/RADARSAT2 data exploitation [11]. All the AO projects started in April 2014, having a 2-year duration.

\section{San Syn project}

The SanSyn (Santorini Synergies- Integration of X and C-band SAR data with GPS measurements and gravity data for monitoring Santorini volcanic complex) project has the Italian INGV as Principal Investigator (PI). Its technical objective is to establish a scientifically sound 
approach for the joint processing of product generated from several SAR sensors, in terms of spatial and temporal resolution and wavelength, customized for monitoring volcanic sites. The focus of this activity is to generate ground displacement maps, using COSMOSkyMed and RADARSAT-2 data, applying interferometric techniques. The $\mathrm{X}$ - $\mathrm{C}$ - band integrated product is validated using in situ deformation data, from permanent GPS stations that assure the coverage of Santorini Volcanic Complex (SVC). Additionally, correlations with gravity data and local seismicity records are explored, aiming at enhancing the understanding of the physical processes that govern Santorini volcano. The basic processing of the SAR imagery is based on Persistent Scatter Interferometry, employing PSInSAR (Persistent Scatterer Interferometric Synthetic Aperture Radar) and SBAS (Small BAseline Subset) techniques.

\section{SFU project}

The Simon Fraser University (SFU) is the Canadian PI of this project (Characterizing volcanic hazard in Latin America), whose areas of interest are the Laguna del Maule and Southern Andes (Chile), the Tungurahaua and the Northern Andes (Ecuador and Perù). The activity is focused on to use COSMO-SkyMed and RADARSAT-2 data to better understand the relationship between volcanic eruptions and ground deformation at volcanoes located in the areas of interest and in addition to improve understanding of the complex processes that drive a magmatic system to eruption. The interferograms provided from both sensors provide an essential tool for understanding how magma moves through the subsurface over time providing clues for hazard assessment/risk mitigation from volcanic eruptions, landslides, and earthquakes.

To reach the objective satellite data are integrated with ground based observations (geologic, geophysical, geochronology, and petrologic) to constrain coupled numerical models for several conjugate processes at different scales.

\subsection{CIDOT Active Volcanoes}

The Active Volcanoes project has been activated in the framework of the multi-target agreement between CIDOT (Centro Interpretazione Dati di Osservazione della Terra), an ASI center of competence in the field of Earth Observation data processing, and JPL.

The activity concerns the investigation of dynamic processes of active volcanoes, in particular the study and optimization of COSMO-SkyMed short revisit time from both ascending and descending orbits in order to maximize source model resolution. Among the selected test sites there are:

1) Kilauea an Mauna Loa volcanoes, Hawaii, to which the unprecedented short revisit time of COSMOSkyMed constellation is applied in order to better characterize volcano dynamics and eruption precursory processes;

2) Copahue volcano, Argentina, that is currently in redalert status and has been in unrest since December of 2012. The high temporal sampling with COSMOSkyMed can improve source model constraints and better track its dynamic processes leading up to more significant eruptions that are anticipated in the future;

3) Laguna del Maule caldera (Chile) whose deformation, still ongoing, started in 2007. COSMOSkyMed data give an important contribution to its deformation source with an uncertain future;

4) Afar Rift, Ethiopia, is one of the two place on Earth where the global mid-ocean ridge system is above sea level. The complex pattern of elasto-plastic surface deformation demands high resolution InSAR observations such as those coming from COSMOSkyMed that, together with its short revisit time, provides excellent opportunities to capture the evolution of the magmatic system;

5) Sierra Negra, Ecuador, whose most recent eruption in October 2005 produced about 120 million cubic meters of lava, causing the center of its caldera subsided about $5.4 \mathrm{~m}$ over 9 days of eruption. The eruption was preceded by Mw 5.4 earthquake due to a faulting event, indicating strong mechanical interaction with magma chamber for which high resolution InSAR observations are required in order to carry out rigorous analysis.

Other volcanoes monitored in this project are Sabancaya (Peru), Vesuvius, Etna, Vulcano (Eolie Islands) and Stromboli.

\subsection{DPC EOLIE}

Activated in 2013 by the Department of Civil Protection, this project foresaw advanced analysis and new technological developments applied in the framework of volcanic and seismic risk scenarios.

SBAS-DInSAR technique is used to process COSMOSkyMed StripMap data on Eolie islands, in particular Vulcano and Lipari, taking advantage of the high temporal resolution of COSMO-SkyMed data.

The purpose of this activity is to provide a detailed analysis about the ongoing deformations and related time series on Vulcano and Lipari islands, with the main aim to support the DPC in the definition of any emergency plan.

\section{CONCLUSIONS}

The COSMO-SkyMed mission, which represents the largest Italian investment in the field of Earth Observation, is a powerful instrument for space observation aimed at environmental monitoring and territory surveillance. Since the launch of the first satellite in 2007, COSMO-SkyMed provided a solid contribution in different application domains: oil spill detection, monitoring of economic and strategic areas, monitoring of sensible sites, such as active volcanoes 
worldwide, seismic areas worldwide, areas subject to subsidence phenomena, glaciers, etc.

In this paper a special focus has been addressed to the contribution provided by COSMO-SkyMed in the framework of volcanic risk monitoring.

A complete overview of the national and international projects in which COSMO-SkyMed data are exploited for the volcanic risk mitigation has been given. In this context COSMO-SkyMed mission has already provided its user community with more than 10.000 products and almost 40.000 scenes over volcanoes worldwide have been acquired.

Actually, the high frequency of COSMO-SkyMed SAR acquisitions makes it ideal for measuring fast changing ground deformations at volcanoes, allowing scientists to detect the complex dynamics of volcanoes and facilitate identification of precursors to potentially disastrous eruptions.

\section{ACKNOWLEDGEMENTS}

The authors wish to thank the e-Geos colleagues for the continuous technical and operational support and all ASI colleagues directly involved or in charge of the projects mentioned above.

\section{REFERENCES}

1. Covello, F., Battagliere, M. L., Coletta, A. (2012). Overview and exploitation of the fully deployed COSMO-SkyMed constellation, Proceedings of 63rd International Astronautical Congress, 1-5 October 2012, Naples, Italy.

2. Grandoni, D., Battagliere, M. L., Daraio, M. G., Sacco, P., Coletta, A., Di Federico, A., Mastracci, F. (2014). Space-Based Technology For Emergency Management: The COSMOSkyMed Constellation Contribution, Proceedings of CENTERIS $2014 \quad$ SARWatch Workshop: Advances in the Science and Applications of SAR Interferometry, 1517 October 2014, Troia, Portugal.

3. Covello, F., Battagliere, M. L., Coletta, A. (2013). The contribution of the COSMO-SkyMed space system in the international context, Proceedings of ESA Living Planet Symposium, 913 September 2013, Edinburgh, UK.

4. Daraio, M. G., Battagliere M. L., Sacco, P., Virelli, M., Coletta, A. (2014). COSMO-SkyMed data utilization and applications, Proceedings of 65th International Astronautical Congress, September-3 October 2014, Toronto, Canada.

5. Sacco, P., Battagliere, M. L., Daraio, M. G., Coletta, A. (2014). The COSMO-SkyMed support to earthquake events. Proceedings of SPIE 9243, SAR Image Analysis, Modeling, and Techniques XIV, 924317, October 21, 2014, doi:10.1117/12.2067234.

6. http://srv1.rm.ingv.it/srv/srv

7. Battagliere M. L., Covello F., Coletta A., (2012). COSMO-SkyMed Background Mission: overview, objectives and results. Proceedings of 63rd International Astronautical Congress, 1-5 October 2012, Naples, Italy.

8. Sansosti, E., Pepe, S., Solaro, G., Casu, F., Acocella, V., Ruch, J., Nobile, A., Puglisi, G., Guglielmino, F., Zoffoli, S., (2012). SAR4Volcanoes: an international ASI funded research project on volcano deformation through new generation SAR sensors. Poster presentation EGU Meeting, Vienna, April 2012.

9. http://supersites.earthobservations.org/index.html

10. Sigmundsson F. et al. (2015). Segmented lateral dyke growth in a rifting event at Bárðarbunga volcanic system, Iceland. Nature, 517, 191-195, doi: 10.1038/nature14111.

11. www.asi.it

12. http://ceos.org/ourwork/workinggroups/disasters/ 